A partir de fragmentos de discurso de pais de jovens que apresentaram uma descompensação psicótica na adolescência, a autora questiona, por um lado, a importância de verificar se haveria, na infância desses jovens, fatores relevantes que pudessem justificar ou serem preditivos da eclosão de uma psicose na adolescência. De outro lado, alerta para os efeitos nefastos de tomar o fato de os pais terem vivido experiências dificeis na sua própria adolescência como um papel determinante na eclosão da psicose do filho.

Adolescência; pais; psicose; crise psicótica

MANDATES OF PARENTS OF ADOLESCENTS IN CRISIS

From parts of the speech of parents of young that had presented a psychosis in the adolescence, the author questions, of a side, the importance of it to verify if would have in the infancy of these young, excellent factors that could justify the psychosis in the adolescence. $O f$ another side, alert for the ominous effect of it taking the fact of the parents to have lived difficult experiences in its proper adolescence as a determinative paper in the spronting of the psichosis in the son. Adolescence; parents; psychosis; psychotic crisis

\section{EVOCAÇÕES DE PAIS DE ADOLESCENTES EM CRISE}

Maria Cicília de Carvalho Ribas

\. longo de anos de trabalho na clínica psicoterápica sempre me chamava a atenção a fala dos pais cujos filhos apresentaram uma descompensação psicótica na adolescência: "tudo estava bem, meu filho era normal e de repente tudo mudou". Este discurso dos pais, sobre a "normalidade" do filho antes da descompensação, sempre nos colocava interrogações, principalmente quando a descompensação era seguida pela entrada em uma psicose franca.

Lembro-me particularmente de uma adolescente que me foi encaminhada por um psiquiatra e chegou ao meu consultório em companhia do pai. Segundo ele, sua filha nunca tinha tido problemas desde que nasceu, tudo estava indo muito bem até que a mãe viajou. No dia seguinte à viagem da mãe, ela começou a ter crises de choro, a falar sozinha, enfim, a falar e a se comportar de uma forma

Psicóloga, Doutora em Psicologia Clínica pela "Université Paris 5 - René Descartes", Coordenadora do Serviço de Terapia Intensiva do CPPL - Centro de Pesquisa em Psicanálise e Linguagem, Membro fundadora do Laboratório de Psicopatologia Fundamental e Psicanálise da UNICAP, Professora do Departamento de Psicologia da UNICAP, Associada na CNHRES, França. 
completamente bizarra. Ele não a reconhecia mais. $\mathrm{O}$ pai e os dois irmãos mostravam-se exaustos e desesperados diante da situação.

A viagem da mãe foi a situação desencadeadora. Resta, que na nossa concepção, uma manifestação psicótica não aparece sob um "céu sereno". Interrogamo-nos, então, acerca da fala do pai ao afirmar que sua filha até então não apresentara problema nenhum.

Quando pensamos nas transformações inerentes ao processo adolescente, nós podemos representar este período da vida como "uma porta aberta" às psicoses. No entanto, a experiência psicótica é uma contingência e não faz parte necessariamente do processo da adolescência. Isto leva a supor a existência de outros fatores, além das mudanças próprias ao processo adolescente, que poderiam criar condições favoráveis ao surgimento de experiências psicóticas na adolescência.

Tal suposição deu origem à tese de doutorado em Psicologia Clínica que desenvolvi na "Université Paris V".

Naquele momento, ao pensar nos fatores que, além das mudanças próprias ao processo adolescente, poderiam criar condições favoráveis ao surgimento de experiências psicóticas, eu estava respaldada na concepção de que deveria haver, na história de jovens que apresentavam uma descompensação psicótica na adolescência, elementos que funcionassem como indicadores de dificuldades já na infância. Efetivamente, foi possível encontrar na história de alguns adolescentes referências a dificuldades de adaptação na creche, problemas no desenvolvimento da linguagem e no estabelecimento de relações com outras crianças etc. Mas percebi que tais dificuldades não eram, absolutamente, significativas em si mesmas e não podiam ser tomadas como indicadoras de coisa alguma.

O seguinte relato sobre o nascimento da filha me foi narrado por Sr. Marc, pai de uma jovem que apresentou um quadro psicótico na adolescência, com quem tive a oportunidade de conversar justamente quando estava iniciando meu trabalho de pesquisa:

"Viviane morreu. Viviane morreu não, não é isto, meu pai morreu três semanas antes do nascimento de Viviane... ela nasceu... é curioso o que estou pensando agora, ela nasceu em julho, ela tinha quase três semanas de atraso, ela deveria nascer duas semanas, três semanas antes e eu creio que não foi um erro do doutor, ela estava atrasada, ela estava atrasada... eu esperava um menino... mas eu não sei se eu estava contente, eu não estava descontente hein, eu tive de início uma reação de decepção porque ela era uma menina e não um menino, bom... se a senhora quiser, numa certa medida, eu coloquei sobre minha filha ao mesmo tempo instintivamente e voluntariamente toda a afeição que minha avó paterna 
tinha por mim. Porque, a senhora veja, era uma mulher que eu amei muito, enfim, é uma pessoa excepcional".

Neste momento da entrevista, lágrimas caíam de seus olhos. Ele se desculpou explicando-me que não era fácil para ele evocar tudo aquilo: "fazia muito tempo que eu não pensava nisto tudo. Ela morreu em 66 ou em 67, eu não sei mais... eu tive tantos problemas eu também, hein, enfim, isto não entra, não tem nada a ver com Viviane, tudo isto foi antes do meu casamento, isto não entra em linha direta, bom isto entra na minha evolução pessoal, mas não concerne Viviane”.

A partir da fala deste pai, decidi abandonar a busca infrutifera de indicadores de dificuldades na infância e comecei a fazer entrevistas com pais nas quais eu pedia simplesmente que me falassem tanto acerca das lembranças que tinham da infância e da adolescência do filho até o momento da descompensação como também sobre as lembranças de sua própria infância $e$ adolescência. Este relato foi um marco na mudança da minha posição.

$\mathrm{Na}$ adolescência, a questão central é o remanejamento das relações anteriormente instituídas. $\mathrm{O}$ adolescente deve reorganizar seu mundo interior. Estas modificações não podem se efetuar sem conflitos, principalmente internos, já que implicam um trabalho de luto, luto de um status e, mais profundamente, de certas imagens de si e dos pais.

A princípio, estes remanejamentos provocarão sofrimento e angústia, mas não outros sintomas. Tal processo coloca em pauta a integridade do ego ou as falhas na sua organização primitiva.

Parece lógico, então, concluir que a descompensação psicótica na adolescência revela fragilidades anteriores. Resta a questão: por que só na adolescência se deu a descompensação? A resposta pode ser dada retomando o que está dito brevemente acima sobre as transformações que a adolescência implica, ou seja, mudanças psíquicas importantes, constituindo, portanto, a adolescência um momento de reorganizações e, por isso mesmo, de certa fragilidade. $\mathrm{Na}$ adolescência é exigido do sujeito assumir sua identidade sexual, a mudança de objeto de amor, uma certa autonomia quanto ao prazer e ao pensamento. Estas novas exigências implicam a afirmação do funcionamento autônomo, de forma nunca exigida antes na infância, quando o ego parental funcionava como ego auxiliar para a criança. Daí, que um certo equilíbrio pode então ser mantido até a entrada na adolescência. Mas, em face das novas exigências, fragilidades são reveladas.

Até agora falamos do que acontece do lado do adolescente. Como bem lembra Cahn (1996), o fracasso radical que uma manifestação psicótica na adolescência indica está certamente ligado, de início e antes de tudo, aos obstáculos internos tais quais vividos pelo adolescente. No entanto, é na adolescência que se revela, de forma particularmente surpreendente, o impacto do ambiente no funcionamento psíquico em razão do papel decisivo que ele tem para todos os envolvidos. Assim, os pais 
também vivem um processo de remanejamento das relações anteriormente instituídas.

É fundamental lembrar, então, como a adolescência é suscetível de colocar os pais e o casal em crise. De certa forma, a criança será lançada no drama pubertário pelos próprios pais ao reagirem de forma dramática às mudanças introduzidas pela puberdade do filho. Para os pais, a puberdade do filho provoca a reativação das etapas de seu próprio desenvolvimento libidinal e obriga-os a se confrontar com suas próprias experiências pubertárias, na forma pela qual eles tentaram resolver seus problemas triangulares, seus movimentos de separação individualizante e a metamorfose de seus corpos de criança. É por isto que a puberdade transforma de modo marcante as relações pais-filho.

As representações dos pais em relação a seus filhos adolescentes revelam, segundo P. Gutton (1990), dois níveis relacionais:

- o da organização triangular edipiana, na qual o adolescente é reconhecido enquanto ser sexuado e suscetível de procriar;

- o da relação dual em que o adolescente se apresenta como um sintoma dos pais.

Ainda segundo o autor, é esperado que os pais passem por uma elaboração psíquica importante e, assim, consigam fazer o reconhecimento da puberdade do filho, deslocar a excitação mobilizada na relação com este filho para um parceiro, reassegurando, desse modo, o tabu do incesto no plano interno e grupal. Desta forma, e só assim, terá possibilidades de se relacionar com o filho numa posição de distância e, ao mesmo tempo, mantendo ligações ternas; jogo de ausência/presença, fundamental para que a adolescência tenha lugar.

Quanto ao nosso estudo, ouvimos diferentes histórias sobre a infância e adolescência do filho e dos próprios pais contadas por estes últimos. Nós descobrimos uma certa coincidência que pode comportar um sentido: os pais escolheram seus cônjuges ao mesmo tempo que saíram, cronologicamente falando, de sua própria adolescência. A forma pela qual a adolescência foi equacionada por estes pais nos ensina sobre a capacidade deles de suportar a rivalidade, de integrar a diferença e fazer face aos seus movimentos pulsionais.

Como exprime bem o Sr. Marc, ele próprio estava com problemas e não pôde se dar conta de que a filha também estava. Ele não podia representar a gravidade da dificuldade com a qual a filha estava se confrontando.

"Eu, o que eu me culpo após este tempo... enfim, mesmo se isto não serve de nada se fazer acusações é de não ter compreendido a situação de minha filha, o momento onde era preciso intervir. Mas, eu tinha meus problemas, tinha meu trabalho, eu tinha 
minha mulher internada em hospital psiquiátrico uma ou duas vezes por ano. E era preciso que eu me ocupasse da garota materialmente, intelectualmente... eu quero dizer que eu não vi o problema chegar. Eu não compreendia estas coisas, eu não sabia que elas tinham tanta importância e que elas iam perturbar a existência dela".

$\mathrm{O}$ que foi se delineando para nós neste estudo e que interessa finalmente destacar aqui é que a carga afetiva com a qual os pais relataram certas lembranças indicava que se tratava de lembranças não-cicatrizadas, cujo pano de fundo são impasses identificatórios, lembranças ainda bastante dolorosas, apesar da passagem do tempo cronológico. Diante do sofrimento frente à eclosão de uma psicose no filho adolescente, são a estas lembranças dramáticas da sua própria adolescência que os pais são remetidos.

Os pais que participaram do nosso estudo, com exceção do Sr. Marc, conheceram seus cônjuges quando estavam com idades entre 16 e 18 anos.

Através do encontro com o cônjuge, existe a possibilidade de mudança e de liberação de antigas fixações em relação aos pais ou irmãos e irmãs. Quando não é o caso, podemos esperar reencontrar na relação do casal, assim como nas relações com os filhos, fantasmas do passado que comportam sempre uma carga mortífera e um caráter de repetição.

Apresento, agora, trechos de falas de alguns pais que participaram da minha pesquisa, que expressam como foram reativados neles o sofri- mento vivido na sua própria adolescência:

"Eu tinha 16 anos, disse-me Sr. Marc, quando deixei a casa de minha avó paterna para ir estudar em Paris. Eu morava com ela desde os oito anos de idade e para mim foi uma ruptura. Em Paris não consegui fazer amigos, não consegui estudar nem passar nos exames. Eu tinha dificuldades de comunicação, para mim era mais fácil trabalhar do que estudar. Abandonei os estudos e fui procurar trabalho. Trabalhei alguns meses num escritório, mas logo fui demitido, o que me deprimiu bastante. Mais adiante consegui um novo emprego.

Conheci minha futura mulher Jeanne quando ela entrou no banco onde eu trabalhava. Ela tinha 18 anos na época e foi minha secretária por um tempo, depois foi trabalhar em outro setor. Eu a achava muito menina. Pouco depois de nos conhecermos, ela se casou com o namorado porque estava grávida. No dia do casamento, seu pai estava operado e ela me pediu que substituísse seu pai e entrasse com ela na igreja. Eu aceitei, ela se casou e três meses depois se separou.

Houve uma reorganização no banco e tempos depois voltamos a trabalhar juntos como na primeira vez que nos conhecemos. Começamos a sair para almoçar juntos, nos víamos freqüentemente. Nesta época, minha avó com quem morei até ir para Paris e que era a mulher que mais amava na família, faleceu. A partir deste instante, meu pai e eu nos aproximamos e estabelecemos uma relação muito 
boa depois de mais de 20 anos de desentendimentos.

Um dia Jeanne me disse que a mãe dela vinha passar férias em Paris e que ela gostaria que já estivéssemos casados quando a mãe chegasse. Assim, nós nos casamos imediatamente, mas a mãe dela nunca veio a Paris. Outra razão para o casamento é que eu queria ter um filho, mas Jeanne não queria engravidar sem estar casada. Para mim, ela quis se casar comigo simplesmente porque eu the lembrava estranhamente seu pai. Após o casamento, o pai de Jeanne não quis mais me ver, rompeu para sempre comigo, desde então nunca mais nos falamos".

"Quando tinha 16 anos, contoume Sra. Mulumba, comecei a me sentir muito angustiada e muito só. Meus pais tinham se separado já há algum tempo, as visitas do meu pai tinham escasseado e minha mãe não dava atenção a mim. Eu vivia pedindo que algo acontecesse para me tirar daquele silêncio, daquele medo, daquela expectativa que eu não sabia nem mesmo de que. Todas estas angústias cessaram em torno dos 18 anos quando conheci meu marido mas estes problemas de angústia voltaram quando meu filho adoeceu".

"Aos 17 anos", relata Sra. Dupuy, "me sentia terrivelmente angustiada, me sentia sufocada com medo de morrer. Meu pai preferia minha irmã, achava ela bonita e de mim falava como a inteligente". Aos 17 anos pegou uma mochila e foi viajar com um amigo. De volta para casa, encontrou um trabalho e aos 18 anos fez outra viagem. Na volta desta viagem, foi morar só. Viveu al- guns meses com um rapaz que amava muito e de quem engravidou mas teve que fazer aborto porque ele não queria ter filhos. Separaram-se e ela conheceu o pai de seu filho. "No começo, não estava apaixonada. Simplesmente foi tudo calculado porque eu achava que ele tinha qualidades para ser um bom pai. Quando fiquei grávida, ele não queria que eu tivesse o bebê, ele ficava dizendo que o bebê ia ficar entre nós dois". $O$ bebê nasceu e alguns anos depois ela engravidou de novo. O marido obrigou-a a abortar. Ela abortou e se separou do marido.

"Eu era filha única", contou-me Sra. Helene, "eu era adorada pelo meu pai. Ele morreu quando eu ia fazer 18 anos e minha mãe nunca se recuperou da morte dele. Logo em seguida eu me casei. Meses depois tive um bebê, me separei e voltei a viver com minha mãe que, ao se ocupar do bebê, reencontrou uma razão para viver. Tempos depois conheci o pai de André. Nos casamos e ficamos muito contentes quando André nasceu. Antes dele eu tinha tido uma gravidez, eram crianças siamesas que nasceram mortas. Não falávamos nunca disto nem entre nós, nem com nossos filhos, nem com a família. O nascimento de André nos aliviou muito. Eu mesma cuidei dele. Ao contrário de meu primeiro filho, o relacionamento de André com minha mãe sempre foi distante".

O pai de André: "Sou filho único e tive pais muito doentes desde sempre, desde criança que me preocupava com a saúde deles. $\mathrm{Na}$ adolescência eu vivia muito sozinho, não tinha amigos nem tempo para 
diversão, pois era eu que cuidava dos meus pais e da nossa casa. Aos 18 anos comecei a namorar com uma mulher que foi o grande amor de minha vida, mas era um amor proibido, ela era casada e voltou para o marido. Eu estava vivendo esta decepção amorosa quando conheci a mãe de André. Nós nos casamos porque ela assim quis, tivemos filhos porque ela assim decidiu. Quando André estava com dez anos, eu reencontrei a mulher que foi o amor de minha vida, ela estava separada do marido. Voltamos a namorar e em seguida fomos morar juntos. A mãe de André nunca se recasou, acho que ela nunca superou a nossa separação".

"Eu sou filha única", contou-me Sra. Christine. "Eu tinha 15 anos quando meu pai morreu. Eu era como meu filho Jean, eu era tímida e tudo mais... mas com a morte do meu pai minha mãe entrou em depressão e eu é que fui trabalhar para tomar conta dela e da casa. Eu fiquei forte, determinada. Aos 18 anos conheci meu marido... Vamos falar do nascimento, então... a senhora quer que eu fale do Jean (filho) ou ... porque a história de Jean tem uma ligação com o comportamento do meu marido, meu marido era, não tem problema eu lhe falar do meu marido porque o problema de Jean vem de lá, ele (o pai) tinha problemas psicológicos desde criança porque sua mãe casou com um homem de quem ela não gostava, ela foi obrigada e finalmente ela engravidou e teve um filho, esta criança não teve amor, não teve afeição, não teve nada. Eu me casei com ele, eu vi que era um homem nervoso, mas naquele tempo eu não sabia o que eram problemas psicológicos como agora... quando eu convenci meu marido a se cuidar, Jean tinha 9 anos. Dos 9 aos 16 anos de Jean eu me ocupei do meu marido. Com 16 anos Jean teve sua primeira crise”. O pai de Jean, com quem também conversei, me conta que o sogro era alcoólatra.

Lembranças de perdas, de desproteção, de desamor, estas falas nos mostram como os pais foram atingidos no momento da crise de seus filhos adolescentes, sendo lançados a se confrontarem com seus próprios sofrimentos.

Como ressaltei anteriormente, a hipótese da existência de problemas na infância que justificassem, ou pudessem prognosticar, a eclosão de uma psicose na adolescência, não ajudava a pensar a situação destes jovens adolescentes, nem contribuía para a produção de novas formas de intervenções clínicas. Desta mesma forma, parece improdutivo tomar a problemática dos pais como representando um papel determinante na psicose dos filhos. Temos verificado em nossa clínica como uma posição que tenha por base a preocupação com as questões relativas à etiologia acentua a culpabilidade dos pais, mobilizando forte resistência para que possam elaborar as suas próprias experiências, ressignificá-las e, assim, se 


\section{Dossiê}

reconhecerem e serem reconhecidos por nós como capazes de cuidar do seu filho.

São muitas as lições e várias as questões a serem ainda desdobradas a partir das conclusões do meu trabalho de tese; algumas já vislumbradas, que possibilitaram inclusive a construção deste artigo, e outras ainda por vir.

\section{REFERÊNCIAS BIBLIOGRÁFICAS}

Can, R. (1996). Adolescence et folie. Paris: PUF.

Gutton, P. (1990). Le pubértaire. Paris: PUF. Ribas, M. C. C. (2000). Une étude clinique sur la capacité de séparation chez des adolescents et jeunes adultes psychotiques. Tese de Doutorado, Laboratoire de Psychologie Clinique, Université Paris 5 - René Descartes, Paris.

Recebido em maio/2002. 